\title{
Practice-based Research is Community Engagement
}

\author{
John M. Westfall, MD, MPH, Lyle J. Fagnan, MD, Margaret Handley, PhD, MPH, \\ Jon Salsberg, MA, Paul McGinnis, MPA, Linda K. Zittleman, MSPH, and \\ Ann C. Macaulay, CM, MD
}

Community engagement has become a major contributor to medical research during the past 10 years and is an essential component of the current National Institutes of Health (NIH) Roadmap and the Clinical and Translational Science Awards program. ${ }^{1,2}$ But, what is a community? And what community gets to be engaged?

Kerr White described one of the major problems with clinical research in the United States as using the tertiary academic medical center as the main location of research ideas and subject recruitment. He pointed out that the vast majority of research was conducted on the $0.1 \%$ of the population who were cared for in the academic tertiary hospital. ${ }^{3,4}$ Coupled with this problem of location was the problem of the approach that did clinical research on subjects, ignoring their unique cultural, ethnic, and geographic identity, and which focused primarily on the interests of the researchers. As a consequence, much of the research was not readily translated into practice, nor was it reflective of clinical problems experienced in non-tertiary settings. Preceding the NIH initiative and now experienced at an accelerated tempo, many researchers have responded to these problems by moving their research enterprise into the community, directly engaging the community in their research and programs. Practice-based research provides a model

Submitted 5 May 2009; revised 5 May 2009; accepted 5 May 2009.

From the High Plains Research Network, University of Colorado, Denver (JMW, LKZ); Oregon Clinical and Translational Science Institute, Oregon Health and Science University, Portland (LJF, PM); University of California, San Francisco, Clinical and Translational Science Institute $(\mathrm{MH})$; and Participatory Research at McGill, Department of Family Medicine, McGill University, Montreal, Quebec, Canada (ACM, JS).

Funding: none.

Conflict of interest: none declared.

Corresponding author: John M. Westfall, MD, MPH, High Plains Research Network, University of Colorado, Mail Stop F496, P.O. Box 6511, Aurora, Colorado 80045 (E-mail: jack.westfall@ucdenver.edu). that mixes scientific inquiry and community engagement. However, practice-based research has faced growing confusion surrounding the terms community and engagement.

\section{Location and Orientation}

What is the community? Is a community a single geographic location or region or neighborhood? Is community a single racial, ethnic, or religious group; a collection of patients with the same disease; or a population defined by multiple characteristics, such as vulnerability in relation to social and clinical characteristics? Can a community be dispersed over a larger geographic area-a state or the nation: a virtual community linked by email or the internet? Can a community be a clinic: the clinicians, nurses, staff, and patients? A significant sticking point in defining community engagement is often defining the characteristics and parameters of the community.

What constitutes engagement? There are no consistent definitions, but one definition we support states that community engagement includes, "The application of institutional resources to address and solve challenges facing communities through collaboration with these communities." Community-engaged scholarship (CES) is a recent evolution of the term community-based research (CBR). ${ }^{6}$ The term engaged recognizes that the work is done with communities and the term scholarship is seen as more positive than research. However, simply using CES or CBR does not ensure full community voice in research governance. Community engagement benefits from using the participatory research principles of shared power and decision making between researchers and community members. Participatory research is the "systematic enquiry, with the collaboration of those affected by the issue under study, for the purpose of education and taking action or effecting social change." 7,8 One frequently used term is community-based par- 


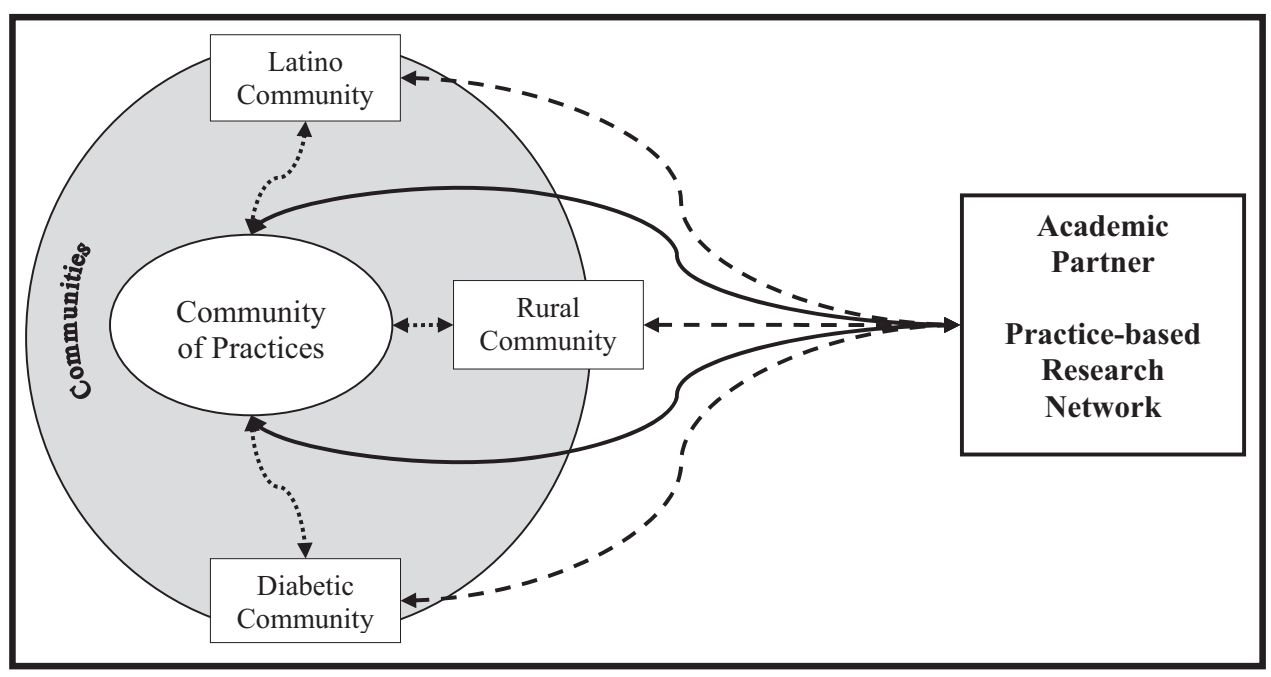

Figure 1. Practice-based research engaging the community. Practice-based research networks (PBRNs) directly engage the medical practice community (solid line) and community members (dashed line). PBRNs may engage the community members through the practice (dotted line). A community may be geographic, demographic, disease specific, or a combination. Numerous other communities exist and may be engaged directly or through the practice (shaded area).

ticipatory research (CBPR); much of the early work in participatory research occurred in the field of health promotion and in neighborhoods and broad community locations, including public health and non-clinical settings. CBPR has become nearly synonymous with community engagement. However, is community the most important element in the community-engagement-participatory-research equation? Has the focus on the neighborhood aspects of community overshadowed the participatory aspects? Participatory research encompasses much more than just CBPR.

Participatory research is not simply about using a group of neighborhoods or community members to push forward a specific research agenda. It is really about an "orientation" to research that embraces the sharing of power. Participatory research is not a method; it is an approach to research governance that aspires to a partnership of researchers and community and a willingness to expand or reframe research questions to increase its relevance to community members, whatever that community may be. Participatory research builds long-term relationships that outlast any specific research project; these relationships form the foundation of a sustained conversation that includes 2-way communication and shared decision making. At its core, participatory research is about conducting research with a group, rather than conducting research on a group, and with a community rather than simply in a community or for a community. All the above stem from-and perpetuate-the orientation that the community, and indeed participatory research itself, are not merely tools at the disposal of researchers but are the core values that drive the research endeavor.

\section{Engaging Community in Practice-Based Research Networks}

Practice-based research (PBR) aspires to the orientation of participatory research and community engagement in 3 significant areas (Figure 1). First, PBR demonstrates the orientation to research that encompasses the participatory approach. Rather than just research in practices, PBR strives to do research with practices, with the physicians, nurses, office staff, and patients. PBR includes the principles of participatory research: trust building, longterm relationships, recognition and incorporation of local expertise and the history of local relationships, shared decision making, and identification of locally relevant clinical questions. ${ }^{9-11}$ The broad spectrum of PBR recognizes that "no single set of principles will be applicable to all partners, that there is a spectrum of partnerships, with full partnership as the ideal for which we strive."12 In this issue of the Fournal of the American Board of Family 
Medicine is an article by Parchman and Munoz ${ }^{13}$ that resulted from this participatory approach. Dr. Munoz is a practicing family physician with an important clinical question. STARNet had the capacity to engage Dr. Munoz and several other practices to ask and answer this clinical question that came directly from the care of patients. Dr. Munoz was a partner for the entire project and co-author on the published manuscript.

Second, PBR engages the community of the practice. That is, each practice includes the elements of a community: collective mission and history, common time together, and a shared social identity. PBR aspires to be a collaborative partnership with practices along the whole research journey, from identification of a clinical problem to the formulation of the research question to the choice of methods, implementation, data collection, analysis, interpretation, and dissemination. In this issue, Froshaug et $\mathrm{al}^{14}$ describe findings from the Prescription for Health Program. Prescription for Health supported 22 PBR networks (PBRNs) to develop unique approaches to addressing unhealthy behaviors and increasing healthy ones. Using the expertise of each practice and each network, Prescription for Health was able to evaluate multiple strategies for improving health, both within the practice and for the patients attending the practice. ${ }^{15-17}$ Levy et $\mathrm{al}^{18}$ and McCord et al ${ }^{19}$ also describe research that engages the primary care practice in various components of the research journey.

Third, PBR occurs within the context of the broader community and neighborhoods and is directly responsive to the needs of the local community in which it exists. ${ }^{17,20,21}$ The people who come to these practices may belong to the same community groups, sports teams, or schools. They may share neighborhood pride and concerns. Even in diverse communities, common concerns about children, aging parents, personal health, and economic struggles may create a shared identity. Because many practices include locally relevant clinical services that address the unique problems faced by their patients, these practices are viewed as a medical home and integral part of the community. Williams et $\mathrm{al}^{22}$ describe the "marriage" of CBPR with PBRNs and list the many advantages they have experienced by involving the broader community in their PBR. They provide an excellent exam- ple of how to engage the community of patients in the research of the practice.

PBR may be an essential step for good translational research. ${ }^{23}$ As quoted widely, "if you want more evidence-based practice, you need more practice-based evidence." ${ }^{24,25}$ Networks have become a widely successful mechanism for organizing PBR within a community context. PBRNs help translate bench discovery and bedside efficacy into effective everyday clinical practice. PBR uses participatory methods to identify the problems that arise in daily practice that create the gap between recommended care and actual care, demonstrate the effectiveness or lack of effectiveness of treatments derived from randomized controlled trials, and provide the laboratory for testing system improvements in primary care to maximize the number of patients who benefit from medical discoveries. PBRNs can provide the environment to help eliminate health disparities by creating true partnerships and blurring the boundaries between clinical research and community-based interventions.

Although PBRNs are effective at communicating the practice-based nature of their research in their publications and PBR has become a successful model for translating research into practice, practice-based researchers have been less effective at communicating the participatory nature of their work. Few articles fully describe the participatory components and the community-engagement orientation of the authors' work. We recommend that authors describe the community engagement and participatory aspects of their research in all manuscripts and editors expect this of their authors and print those portions of the manuscripts. Online supplements may provide a venue for robust description of the community engagement efforts that result in peer-reviewed publications from PBRNs.

\section{Practice-Based Research Supports Clinical and Translational Science}

PBR is community engagement and provides an effective conduit to a population of patients and the members of the broader community in which the practice resides. PBRNs may serve as a logical introduction for academic researchers to begin collaborating with communities and engaging clinicians, patients, and community members. We believe that the host of new Clinical Science and 
Translational Centers and Institutes funded by the NIH that approach research with a collaborative, bidirectional perspective will find an eager and supportive community of researchers, clinicians, patients, and community members in their local and regional PBRNs. A recent survey of PBRN Directors and the Clinical and Translational Science Award Community Engagement Directors emphasized that PBRNs provided more than just expanded access to research subjects. PBRNs also presented opportunities for the academic institution to build relationships with the community (Fagnan, personal communication, March 10, 2009). Westfall et $\mathrm{a}^{20}$ reported that approximately half of the PBRNs surveyed in the United States also engaged community members in addition to clinic staff. PBRNs support the goals of the Clinical and Translational Science Awards to "effectively engage communities in the translational research process via bidirectional dialogues." 1

PBR and PBRNs have solved 2 of the major problems that have vexed clinical researchers for decades. PRBNs solved the "location" problem by moving the research into community practices, where most people get most of their care most of the time, and addressing important clinical questions with large and diverse populations. ${ }^{23} \mathrm{PBR}$ has solved the "orientation" problem by using the principles of community engagement and conducting research with their communities of practices, clinicians, patients, and community members so that the research is highly relevant. PBR may be an effective partner for research that truly engages the community to ask and answer those questions that are most important to the community's members.

\section{References}

1. Clinical and Translational Science Awards. Community Engagement Key Function Committee. Available at: http://www.ctsaweb.org/index.cfm?fuseaction= committee.viewCommittee\&com_ID=3. Accessed May 12, 2009.

2. Zerhouni E. Medicine. The NIH Roadmap. Science 2003;302:63-72.

3. White KL, Williams TF, Greenberg BG. The ecology of medical care. N Engl J Med 1961;265:885-92.

4. Green LA, Fryer GE Jr, Yawn BP, Lanier D, Dovey SM. The ecology of medical care revisited. N Engl J Med 2001;344:2021-5.

5. Community-Campus Partnerships for Health. Linking scholarship and communities: report of the
Commission on Community-Engaged Scholarship in the Health Professions. 2005. Available at: http:// depts.washington.edu/ccph/pdf_files/Commission \% 20Report\%20FINAL.pdf. Accessed May 12, 2009.

6. Community-Campus Partnerships for Health. Community-engaged scholarship. 2009. Available at: http://depts.washington.edu/ccph/scholarship.html. Accessed April 20, 2009.

7. Mercer SL, Green LW, Cargo M, et al. Appendix C: reliability-tested guidelines for assessing participatory research projects. In: Minkler $M$, Wallerstein $\mathrm{N}$, eds. Community-based participatory research for health: from process to outcomes. San Francisco (CA): Jossey-Bass; 2008:407-18.

8. Mold JW, Pasternak A, McCaulay A, et al. Definitions of common terms relevant to primary care research. Ann Fam Med 2008;6:570-1.

9. Green LA, Dovey SM. Practice based primary care research networks. They work and are ready for full development and support. BMJ 2001;322:567-8.

10. Green LA, Hickner J. A short history of primary care practice-based research networks: from concept to essential research laboratories. J Am Board Fam Med 2006;19:1-10.

11. Agency for Healthcare Research and Quality. AHRQ support for primary care practice-based research networks (PBRNs): fact sheet. Revised May 2006. Available at: http://www.ahrq.gov/research/ pbrn/pbrnfact.htm. Accessed August 24, 2006.

12. Macaulay AC, Nutting PA. Moving the frontiers forward: incorporating community-based participatory research into practice-based research setworks. Ann Fam Med 2006;4:4-7.

13. Parchman ML, Munoz A. Risk factors for methicillin-resistant Staphylococcal aureus skin and soft tissue infections presenting in primary care: a South Texas Ambulatory Research Network (STARNet) Study. J Am Board Fam Med 2009;22:375-9.

14. Froshaug DB, Dickinson LM, Fernald DH, Green LA. Personal health behaviors are associated with physical and mental unhealthy days: a Prescription for Health (P4H) Practice-based Research Networks Study. J Am Board Fam Med 2009;22:368-74.

15. Annals of Family Medicine (2006) Supplement dedicated to the Robert Wood Johnson Foundation's Prescription for Health program conducted solely in practice based research networks.

16. Etz R, et al. Bridging primary care practices and communities to promote healthy behaviors. Am J Prev Med 2008;35:S390-7.

17. Green L, Cifuentes M, Glasgow RE, Strange KC. Redesigning primary care practice to incorporate health behavior change: prescription for health round-2 results. Am J Prev Med 2008;35:S347-9.

18. Levy BT, Hartz A, Woodworth G, Xu Y, Sinift S. Interventions to improve osteoporosis screening: an Iowa Research Network (IRENE) Study. J Am Board Fam Med 2009;22:360-7. 
19. McCord G, Pendleton BF, Labuda Schrop S, Weiss L, Stockton L, Hamrich LM. Assessing the impact on patient-physician interaction when physicians use personal digital assistants: a Northeastern Ohio Network $\left(\mathrm{NEON}^{\circledR}\right)$ Study. J Am Board Fam Med 2009; 22:353-9.

20. Westfall JM, VanVorst RF, Main DS, Herbert C. Community-based participatory research in practicebased research networks. Ann Fam Med 2006;4:8-14.

21. Van Vorst RF, Araya-Guerra R, Felzien M, et al. Rural community members' perceptions of harm from medical mistakes: a High Plains Research Network (HPRN) Study. J Am Board Fam Med 2007; 20:135-43.

22. Williams RL, Shelley BM, Sussman AL, on behalf of
RIOS Net clinicians. The marriage of communitybased participatory research and practice-based research networks: can it work? - A Research Involving Outpatient Settings Network (RIOS Net) study. J Am Board Fam Med 2009;22:428-35.

23. Westfall JM, Mold J, Fagnan L. Practice-based research-"blue highways" on the NIH Roadmap. JAMA 2007;297:403-6.

24. Green LW. Public health asks of systems science: to advance our evidence-based practice, can you help us get more practice-based evidence? Am J Public Health 2006;96:406-9.

25. Lawrence W. Green. Last revised December 28, 2006. Available at: http://www.lgreen.net/authors/ lwgreen.htm. Accessed May 12, 2009. 